\title{
ENTREVISTA COM JACK GOODY
}

\author{
Maria Lúcia Pallares-Burke \\ Peter Burke \\ University of Cambridge - Reino Unido
}

\section{Nota dos organizadores}

Esta entrevista, realizada em junho de 2004, por Maria Lúcia PallaresBurke e Peter Burke - historiadores de Cambridge, especialmente para Horizontes Antropológicos - focaliza a importância do tema da cultura escrita na trajetória intelectual do eminente antropólogo inglês Jack Goody, nascido em 1919. Conhecido entre os antropólogos por sua importante atuação como africanista e etnohistoriador, Goody notabilizou-se para o grande público como um dos teóricos da "grande partilha" entre oralidade e escrita. Goody tem defendido, com bastante coerência e originalidade, que no âmago da cultura escrita habita uma espécie de "razão gráfica" que sempre faz a diferença, desde que aparece e se dissemina. Ficamos sabendo que a preocupação com a escrita persegue-o desde que se viu sem nenhum livro em campos de prisioneiros, durante a Segunda Guerra. Como um profeta não reconhecido em sua própria terra, não é sem um certo desencanto que Goody recorda a pouca aceitação de seus trabalhos sobre a escrita entre os antropólogos - ao contrário de sociólogos, historiadores e psicólogos, admiradores da primeira hora. Capaz de sentir-se à vontade tanto entre nativos de tribos africanas quanto entre os antigos gregos, semitas e egípcios, é com notável vigor intelectual que Goody rebate as objeções historicistas e relativistas mais recentes à tese da importância radical da cultura escrita, a ele associada, assim como enfrenta abertamente a comparação entre a escrita e as novas tecnologias virtuais.

Peter Burke: Antes de conversar sobre cultura escrita, permita-me que lhe faça uma pergunta mais geral: como você se situa na antropologia britânica? Qual o seu lugar nessa tradição? De quem você está mais próximo, ou mais distante? 
Jack Goody: Eu estava mais próximo do grupo de Meyer Fortes. Desde muito cedo estava interessado pela abordagem comparativa por causa do problema da cultura escrita. Mas, provavelmente, de uma forma diferente da maioria das outras pessoas. Não consigo lembrar de muitos outros além de Fortes e Freddie Bailey que, nesse momento, estavam interessados no trabalho comparativo, embora num sentido mais formalista do que eu. Estava interessado, mais especificamente, nas dimensões históricas da comparação. Nessa questão sempre me senti mais próximo de pessoas do outro lado do Atlântico, como Eric Wolf, Sidney Mintz e Marshall Sahlins, nos Estados Unidos.

Peter Burke: Então é mais ou menos a grande tradição da sociologia histórica comparativa?

Jack Goody: Sim. Eu fui criado numa época em que as pessoas olhavam com horror para o trabalho dos antropólogos do século XIX, como Tylor, Frazer e outros... Eu mesmo nunca olhei para o passado dessa forma. Sempre achei que era importante olhar para o que eles faziam, em que tipo de problemas estavam interessados. Recentemente, estive com o grupo de Chris Hann, em Berlim, e ele me disse "gostaria que você falasse sobre o seu conceito de Eurásia”. Então falei para eles, mas, no final, fiquei preocupado, porque várias pessoas perguntaram "como isso se relaciona com o nosso trabalho de campo?” Eles não haviam pedido para que eu falasse sobre trabalho de campo. Pediram-me que falasse sobre a Eurásia, e eu falei sobre generalidades, mais do que sobre questões específicas. Parece um pouco estranho. Suponho que sempre houve esse dilema na antropologia. Algo semelhante acontece quando se trata de documentos históricos: você mergulha nos documentos e depois quer olhar de fora e extrapolar. E sempre há quem diga "por que você está tentando ir além do documento histórico, além do trabalho de campo?” Eu respondo “bem, é nessa direção que o meu interesse me leva".

Maria Lúcia: Permita-me fazer uma pergunta sobre a cultura escrita. Como você estava falando em nossa conversa antes da entrevista, a experiência de ter-se encontrado sem nenhum livro quando era prisioneiro de guerra, primeiro no Oriente Médio e depois na Itália, foi de crucial importância no seu interesse pela cultura escrita e no seu trabalho com Ian Watt. 
Jack Goody: Sim, de fato.

Maria Lúcia: Então, ele foi seu principal interlocutor? Ou houve outros interlocutores nesse debate?

Jack Goody: Sim, porque tanto ele quanto eu ministramos aulas de Literatura Inglesa. Conhecíamos F. R. Leavis muito bem. Sua esposa tinha escrito um livro chamado Fiction and the Reading Public. Nesse livro havia um argumento importante sobre a ampliação do público leitor por meio da educação, particularmente intensificado pelo advento da imprensa. Isso transformou a natureza da literatura, do romance, do público leitor de romances e assim por diante. Ian Watt estava trabalhando com o romance inglês, mais especificamente a relação entre a fiç̧ão realista, o advento da imprensa e a disseminação dos livros. Quando fui a campo não estava interessado apenas nesse tipo de mudança que acontecia nos meios de reprodução e de comunicação, mas também na diferença entre as sociedades letradas e as não letradas. Era nesse ponto que as nossas experiências como prisioneiros de guerra convergiam. Então, ele sugeriu que quando eu fosse a campo pensasse sobre essa questão. Foi o que fiz quando fui à África. Assim que retornei, voltamos a conversar sobre o tema. Mas acredito que não havia mais ninguém naquele momento - que eu me lembre - que estivesse interessado nesse tipo de questão. Ele foi a pessoa que mais me estimulou. Mas a base de tudo foi aquele material de Leavis sobre ficção e o público leitor.

Maria Lúcia: Mas depois que seu trabalho foi publicado aumentou muito o interesse sobre o assunto. Ou não?

Jack Goody: Houve interesse por parte de algumas pessoas. Mas não houve uma grande aceitação entre os antropólogos. Produzi um livro tendo como base alguns seminários que ministrei quando estava trabalhando no African Studies Center, e consegui que alguns antropólogos fizessem suas contribuições sobre a influência da cultura escrita nas populações por eles estudadas. Mas eles só fizeram isso porque eu lhes pedi. A resposta dos antropólogos foi bem menos efetiva do que a dos sociólogos que trabalhavam com sociologia comparada. E mais, o artigo - The Consequences of Literacy - que Ian Watt e eu escrevemos, publicado em Comparative Studies in Society and History, teve um impacto bem maior 
entre sociólogos e historiadores do que entre os antropólogos. Nenhum antropólogo daquele grupo veio me procurar para dizer "quero continuar trabalhando com este tema, com as mudanças nas formas de comunicação e o que elas significaram para aquelas populações”. Ninguém, naquela época, pensou, nem mesmo em termos gerais, em estudar como a escrita tinha influenciado um grupo de esquimós. Ou seja, o interesse pelo assunto começou a surgir mais tarde. De fato, quando escrevi o livro sobre cultura escrita em sociedades tradicionais, consegui publicá-lo pela Cambridge University Press graças a Michael Black, que mais tarde veio a se tornar o presidente da editora. Nesse período ele estava em Cambridge, ensinando Literatura Inglesa e se interessou pelo assunto. Black de fato ajudou muito na publicação do livro. Mas não diria que a crítica dos leitores foi das mais favoráveis. Lembro inclusive de um comentário que dizia "no livro tem antropólogos, historiadores, etc., tudo misturado". Eu tinha publicado um texto de Roger Schofield e todos me congratularam por ter conseguido sua contribuição. Mesmo assim, um leitor achou que estava tudo muito misturado.

Maria Lúcia: Misturando história e antropologia...

Jack Goody: Misturando gêneros.

Maria Lúcia: Isso foi em 1963, não foi?

Jack Goody: Sim. Acho que foi em 1963. Outras pessoas também se interessaram, como o meu amigo Moses Finley, que foi muito prestativo e atencioso. Mas não houve, mesmo, grande impacto entre os antropólogos naquela época. De fato, nem naquela época nem nunca. Conheço duas pessoas que estão fazendo uma espécie de Festschrift para mim em Toronto. São dois psicólogos, David Olson, que escreveu The World on Paper, e Michael Cole, que escreveu um livro sobre a escrita entre os Vai da Libéria. Mas não penso que os antropólogos estivessem realmente interessados no assunto.

Maria Lúcia: Desde aquela época algo mudou em sua concepção sobre as conseqüências da cultura escrita?

Jack Goody: Sim, mudou, até certo ponto. Quando comecei, minha concepção sobre o alfabeto era por demais eurocêntrica. Havia um sujeito chamado 
Diringer, em Cambridge, que possuía um museu do alfabeto.

Maria Lócia: Um museu do alfabeto? Que interessante!

Jack Goody: Nós estávamos muito interessados no alfabeto grego. E foi assim que começamos, porque éramos ingleses. Escrevemos um ensaio que investigativa o quanto a escrita alfabética é devedora dos gregos. Muitas das coisas que escrevi de forma muito sucinta eram, de fato, muito mais profundas e amplas. Descobrimos que outras formas de escrever eram capazes de produzir resultados não idênticos, mas semelhantes.

Maria Lúcia: Ah! OK!

Jack Goody: Então comecei a me interessar por outras formas de escrever. Mas, naquela época, tanto eu quanto Watt acreditávamos que outros tipos de escrita, como a chinesa, por exemplo, eram restritivas em vários aspectos. De fato, há alguns anos, estive no Japão. Estava falando sobre escrita alfabética e eles me disseram "o futuro da escrita é a escrita chinesa. Assim todos poderemos escrever, nas nossas próprias línguas, usando o mesmo tipo de grafia e poderemos nos comunicar mutuamente!" Um japonês, sob determinadas circunstâncias, escreve uma mensagem em japonês com grafia chinesa e um chinês é capaz de lê-la.

Maria Lúcia: Eles não conseguem se comunicar oralmente entre si, mas podem se ler mutuamente?

Jack Goody: Certo. O que eu quero dizer é que eles estavam querendo nos convencer de que o futuro da escrita estava num sistema gráfico de sinais daquele tipo, que não é alfabético, nem fonético, e que nesse sentido está divorciado da linguagem fonética. Seria um sistema puramente visual de sons, e assim o mundo todo poderia se comunicar. Pense no trabalho que pouparia à União Européia. Os europeus têm 72 combinações de linguagens para traduzir, ou talvez mais do que isso. Naquela época eu pensava de forma muito semelhante a Lênin, quando dizia que o alfabeto seria a revolução do Oriente. Mas depois descobri que o partido que se opunha a Moscou, ou seja, o Partido Comunista de Mao, era a favor de manter a linguagem tradicional, e estavam talvez certos, no caso da China, pois com todas as línguas diferentes existentes na China, eles seriam capazes de manter a unidade tendo um único tipo de escrita. Portanto, mudei de opinião. 
Mas ainda acho que o que aconteceu na Grécia teve alguma coisa a ver com uma mudança mais profunda, relacionada à maior disponibilidade da cultura escrita para as grandes massas. Isso tudo teve muito a ver não apenas com o que aconteceu na Grécia, mas também por que a Grécia tornou-se um modelo para a posteridade.

Peter Burke: Então, a pergunta que resulta de tudo isso é: em que medida o campo de estudos da escrita mudou desde que você começou a publicar seus trabalhos? Qual a sua opinião sobre a contribuição dos trabalhos posteriores ao seu? Você concorda com a opinião de Geoffrey Lloyd, para quem o debate oral foi muito importante para a revolução do pensamento grego e que não foi apenas uma conseqüência da cultura escrita?

Jack Goody: Bem, Geofrey e eu discordamos, durante muito tempo, sobre esse assunto. Enquanto ele enfatiza a retórica eu acredito que esta é, em parte, conformada pela escrita, ou seja, pela formalização do discurso. Se analisarmos a sua fala [Maria Lúcia] e a de Peter, comparada com a de outras pessoas em Cambridge, você perceberá que seus padrões de discurso são muito diferentes daqueles das pessoas que não passam a maior parte do tempo lendo e escrevendo. Não quero dizer que a fala não possa ser elaborada sem a escrita, mas acredito que esta última é muito importante na elaboração do discurso. O fato é que algo importante aconteceu na Grécia, precisamente lá. Claro que já havia uma cultura escrita no período micênico. Eles sempre tiveram alguma forma de escrita. Há evidências, no entanto, de que se tratava de uma escrita menos sofisticada. Eles tinham o alfabeto, mas ele [Geoffrey] também reivindica que os gregos eram fortemente influenciados por grupos egípcios e israelitas. Eles não tinham, de fato, algo próprio. Quero dizer que tradições inteiras de fala e de escrita estavam se desenvolvendo naquela época no Oriente Médio. Portanto, não eram os gregos os únicos que estavam desenvolvendo esse tipo de coisa. Eu tenho lido seus trabalhos e conversado muito com ele sobre o alfabeto grego. Ele estava convicto de que havia muito mais do que um simples acréscimo dos gregos ao alfabeto fenício, que o teria modificado a fim de que pudesse ser usado. E, pensando bem, a Bíblia toda foi escrita em um alfabeto que, tal como o fenício, não tinha símbolos para as vogais. O nosso argumento, meu e de Watt, era de que a ausência de símbolos para as vogais significava que havia muita redundância no sistema, o que facilitava os mal-entendidos. Mas 
isso não é realmente verdade, ou seja, pode ser verdade de um modo parcial, mas não quando as palavras são contextualizadas. Por exemplo, a Bíblia... um enorme tratado produzido não no alfabeto grego, mas no semítico. Acredito que a interação entre oratória e formas de escrita importadas já acontecia há muito tempo no Oriente Médio. A tese de Geoffrey é que a influência do Egito sobre a Grécia é muito maior do que se costuma pensar. De minha parte creio que a formalização do discurso está relacionada ao que acontece na cultura escrita. Esta formaliza a linguagem de várias maneiras. Mas eu sempre me pergunto se a Grécia teve, de fato, uma tradição especial de debate oral, que eles mantiveram em suas assembléias. Ou seja, não acredito que a explicação da mentalidade grega, do gênio grego, possa dar conta disso. Pode ser que tenha havido tipos particulares de discussões na Grécia democrática que provocaram isso, mas eu suspeitaria mais do que meu amigo Moses [Finley] sobre a contribuição da democracia para a Grécia. Ou seja, parece que Tiro, que deu origem a Cartago, tinha dois sistemas de conselhos. A gente nunca escuta falar sobre isso, mas eles escolhiam duas pessoas a cada ano e tinham um sistema democrático naquela época. E havia também outros lugares nas proximidades que tinham essa tradição de discutir. No que diz respeito à democracia, acredito que quem escuta qualquer discussão em uma tribo acéfala da África chega à mesma conclusão: que se trata de pessoas que se ocupam em discutir seus próprios problemas sem ninguém a lhes impor nada. Acho que Ibn Khaldun estava certo quando dizia isso.

Maria Lúcia: Quem?

Jack Goody: Ibn Khaldun. Ele era da Tunísia.

Peter Burke: Um historiador muçulmano do século XIV.

Jack Goody: Um historiador da Tunísia, freqüentemente descrito como um dos primeiros sociólogos. Ele elaborou uma espécie de história universal. Um dos seus principais temas era a diferença entre a forma de governo dos beduínos e a das cidades. Os beduínos tinham um tipo diferente de solidariedade, que resultava de sua organização igualitária. Eles discutiam idéias, argumentavam, enquanto que os citadinos tinham um sistema baseado num tipo de autoridade consagrada. Minha impressão é que muito provavelmente isso se relacionava ao fato de que essas pessoas faziam anotações sobre o 
assunto que iriam falar nas assembléias, organizando o seu discurso por escrito. As palavras são muito confusas. Quando falo de oralidade, estou geralmente falando de sociedades orais, ou de culturas orais, no sentido de culturas que não têm uma forma de linguagem escrita. Como se sabe, Homero escreveu usando a linguagem oral como nós o fazemos, na nossa sociedade alfabetizada. É equivocado tomar essas formas de linguagem oral e projetá-las para o passado, para as culturas puramente orais, porque elas sofreram transformações significativas em vários aspectos. Sei que falo de uma tradição oral desde uma cultura letrada porque não conheço outra forma de expressar isso. Mas, de fato, penso que as coisas mudaram nesse sentido e de um modo muito substancial. Trabalhos muito interessantes foram realizados na Iugoslávia por Milman Parry e um outro autor, que escreveu The Singer of Tales.

Peter Burke: Albert Lord.

Jack Goody: Sim, Albert Lord. Eles mostram que os dados que estavam recolhendo nos Bálcãs eram semelhantes aos versos de Homero, o que confirmaria que Homero era analfabeto. Mas essas pessoas dos Bálcãs não eram analfabetas. Longe disso, elas freqüentavam escolas, escolas gregas, algumas delas, e estavam em contato com a cultura letrada. Por isso eu penso que suas formas de contar estórias mudaram. Então quando você as compara e diz “oh, ele se parece com Homero", eu digo "sim, provavelmente, mas isso mostra apenas que a escrita grega já era importante para Homero naquele momento, e não o contrário”.

Peter Burke: Permita-me lhe dar um outro tipo de exemplo, desta vez de um antropólogo que trabalha com a escrita de uma outra geração. Você acha que a abordagem de Brian Street é diferente? Trata-se de uma nova forma de estudar a escrita mediante o trabalho de campo? Quão diferente ela é da sua própria abordagem?

Jack Goody: Bem, eu não tenho lido nenhum dos trabalhos de Street recentemente. Ele era, talvez, um dos maiores críticos do tipo de trabalho que eu fazia inicialmente. Penso que ele não leu com muito cuidado algumas das coisas que escrevi. Ele trabalhou no Irã alguns anos atrás e veio para o seminário que organizei em Cambridge. Então, acredito que eu o incentivei a trabalhar nessa direção. Penso que se pode pesquisar a cultura escrita 
diretamente por meio do trabalho de campo. Street não estava tão impressionado com a importância da cultura escrita. Nunca entendi como os antropólogos, tão dispostos a aceitar que a linguagem é um aspecto crucial da humanidade, negligenciem coisas que resultem das transformações dessa linguagem. Street não concordava com isso, porque ele trabalhou numa região islâmica. Ele não aceitava que os grupos com os quais ele trabalhou não eram como os outros grupos estudados por outros antropólogos. Eu acredito que o Islã faz diferença, não apenas do ponto de vista religioso pois o islamismo é uma religião baseada na escrita - mas também em outros aspectos, como formas de governo, de matrimônio, etc. Então não sei a qual aspecto do trabalho de Street você se refere.

Pełer Burke: Eu estava especialmente interessado na possibilidade de usar o termo "escrita" no plural. Numa certa aldeia poderá haver várias escritas, já que as pessoas aprendem uma forma de escrita na escola corânica, depois vão a uma escola de contabilidade e aprendem uma outra forma de escrita, e isso de um modo segmentado.

Jack Goody: De fato, isso acontece em vários lugares. É o tipo de trabalho que eu fiz, embora não com muita profundidade, com Michael Cole, na Libéria. Era uma situação muito interessante porque, na Libéria, eles têm uma escrita arábica para os versos religiosos, uma escrita inglesa na escola e a escrita Vai, inventada em 1819, uma escrita silábica que usavam para escrever cartas entre si. Então, Mike Cole observou essas diversas formas de escritas, usadas em diferentes contextos, e tentou extrair algum tipo de tendência geral que atravessasse toda ela. Acredito que ele estava equivocado, pois cada escrita dependia muito do contexto. Ou seja, é o fato de se escrever numa linguagem específica o que interessa, porque escrever, como falar, é significativo no contexto em que se escreve e se fala. Eles [Street e Cole] afirmavam que não existem características gerais, psicológicas que sejam as mesmas em todas essas formas diferentes de leitura. E, portanto, portanto, nenhum efeito geral poderia ser atribuído à influência da cultura escrita. Bem, isso me parece uma conclusão absurda. A escrita teve sim muitas conseqüências. Eu escrevi um artigo, mais tarde, afirmando que eles [Cole e Scribner] estavam assumindo uma posição ahistórica em relação à escrita e às formas como ela tinha influenciado os Vai. Penso que eles foram específicos demais em relação aos testes 
psicológicos e de memória e outras coisas do gênero. De fato, algumas coisas interessantes resultaram disso, como, por exemplo, os muçulmanos que não entendiam a língua árabe escrita e que aprenderam a ler totalmente de cor, sem entender, apenas olhando as palavras escritas nas páginas, tiveram os melhores resultados nos testes de memória. Nesse sentido a escrita para eles carecia totalmente de significado, era apenas uma técnica. Eles a usavam a fim de desenvolver sua capacidade de memorizar. Ela não substituiu nem acabou com sua memória, ao contrario, ajudou a desenvolvêla. Havia pessoas não alfabetizadas assim como outras que conheciam três tipos de escrita. Por isso, acho que havia coisas muito importantes nesse estudo, mas eles nunca olharam para os aspectos históricos da escrita. Eu sempre pensei, como se poderia falar da escrita sem pensar nas pilhas de livros que temos aqui nestas prateleiras ou na biblioteca? Ou seja, a escrita é muito importante para nós de muitas maneiras, como formas de obter informação e muito mais. Mas eu desde o início tentei colocar as coisas num contexto histórico... que escritas diferentes significam coisas diferentes. Que a escrita alfabética serve para algumas coisas e outros tipos de escrita servem para coisas diferentes. O que era particularmente interessante era a facilidade com que a escrita na primeira língua (o Vai) era ensinada. Ela era ensinada informalmente, e tanto quanto eu saiba, o único lugar em que ocorria dessa maneira. A escrita parece se converter facilmente em sistemas de ensino, onde quer que você esteja, seja na China, na Índia, ou num país islâmico. As pessoas criam sistemas escolares, mas os Vai prescindiam dele. Quando chegavam na idade em que queriam comunicarse ou escrever em Vai, iam até um tio, ou até qualquer pessoa, e diziam "poderia me ensinar a escrever isto?" E tudo acontecia muito facilmente. Mike Cole e eu estávamos especialmente interessados em tudo isso, porque naquela época estávamos tentando imaginar como lidar com a aversão à aprendizagem da leitura e escrita que encontrávamos em algumas escolas do mundo ocidental. E argumentávamos que valeria a pena experimentar um sistema no qual as pessoas passassem a escrever em diferentes idades, isto é, que não todas começassem a escrever com a mesma idade. Dessa maneira, tornaríamos a aprendizagem da escrita um ato mais voluntário.

Maria Lúcia: Um pouco como Rousseau.

Jack Goody: Sim, algo assim. 
Maria Lúcia: Você estimularia a necessidade...

Jack Goody: Sim, teríamos que nos basear nisso. E escrevi um artigo, numa revista canadense, sobre como ensinar as pessoas a encontrar uma forma mais voluntária de aprender a ler e escrever. Mas nisso havia uma boa influência da experiência Vai e do fato de que os próprios Vai tinham esses diferentes tipos de escrita como se fossem linguagens diferentes. Eles usavam uma escrita silábica, a qual era facilmente ensinada. Ou seja, uma escrita silábica é, em certo sentido, muito mais fácil de ensinar do que uma escrita alfabética. E tudo indica que ela era ensinada dentro da família.

Maria Lúcia: Vamos falar agora de religião. Você escreveu sobre as Religiões do Livro, como o judaísmo, o islamismo e o cristianismo. E sobre as diferenças entre essas religiões e as religiões de transmissão oral. Seria justo dizer que as Religiões do Livro são mais inflexíveis e intolerantes do que as outras?

Jack Goody: Sim, isso é realmente interessante, eu estava pensando sobre isso há alguns dias atrás. Quero dizer que o que nós temos nas nossas sociedades - que geralmente são sociedades letradas - é um conjunto maior e mais acelerado de mudanças em andamento, mais do que em outras sociedades, mas isso não se aplica à religião. Ou seja, originalmente nós tínhamos este (maldito) livro que foi escrito há dois mil anos. E os muçulmanos estão fazendo exatamente a mesma coisa! E essas pessoas, os talibãs, não estão fazendo o que deveriam em nenhum padrão malinowskyano, ou seja, ajustar seus mitos a fim de que possam se adaptar às mudanças da sociedade. Eles mantêm seu maldito mito e deixam esse mito dominá-los ordenando "você não deve olhar televisão" e outras coisas do gênero. E isso é algo muito interessante e extraordinário. Se tomarmos os grupos que estudei na África, do ponto de vista de sua tecnologia ou de seus sistemas de cultivo, todos são muito parecidos. Mas, quanto às suas práticas religiosas, as diferenças são enormes. E houve muita invenção. Na região em que trabalhei havia práticas e cultos muito diferentes numa área muito restrita. Conheci, inclusive, pessoas que inventavam santuários. Elas eram muito pragmáticas nesse sentido. Houve também muitas mudanças, muita flexibilidade, nesses santuários. Era comum eles dizerem: "fomos à floresta e tivemos uma experiência" - coisas semelhantes às que se vêem na América do Norte - "e ao voltar, trouxemos aquela árvore, aquele 
arbusto, ou algum tipo de máscara nova”.

Também fiquei um tanto chocado ao perceber o quão inflexível pode ser o cristianismo (assim como outras religiões), e os fundamentalismos evidenciam isso. Do meu ponto de vista as pessoas se voltam para uma palavra escrita que já não tem grande importância. Ela é importante para elas, então elas tentam torná-la relevante para todos. Logicamente, o mito deveria mudar, acompanhando as mudanças da sociedade. Mas nesse caso ele não muda, ele permanece estático. Não quero dizer que não esteja sendo interpretado de forma diferente; está sim. Mas, por outro lado, sempre existe a possibilidade de que chegue alguém, como na época da Reforma, e diga que estão fazendo tudo errado. Tem sempre esse retorno à palavra escrita. Alguém no Texas poderá pensar que Jerusalém pertence aos cristãos ou algo assim, só porque um livro escrito há muito tempo atrás diz isso. E isso com certeza irá influenciar suas campanhas.

Sobre esse assunto é relevante o material que publiquei recentemente no terceiro volume do meu livro...

Maria Lúcia: O Mito do Bagre.

Jack Goody: Sim, acabo de lançar o terceiro volume, que denominei The Mytth Revisited: The Third Bagre, que publiquei nos Estados Unidos pela Carolina University Academic Press. É um livro grande, com o restante das fitas transcritas e uma introdução que eu mesmo escrevi.

Maria Lúcia: Você tem ido a Gana?

Jack Goody: Fui lá recentemente, mas não por causa do livro. Eu tenho essas fitas já faz 20 anos. Leva muito tempo para transcrever tudo isso. Embora agora me pareça um absurdo pensar isso, fui para lá com a idéia de que esses mitos foram passados intactos de geração em geração. A única coisa que estou disposto a admitir é que grandes mudanças acontecem, e de forma extraordinária. Somente eu sou capaz de vê-las, porque todas as pessoas de lá, a menos que eles leiam o que escrevi, acreditam que o mito continua o mesmo. Eles vão falar que o mito é sempre o mesmo, único. Entretanto, as diferenças são enormes, com exceção das partes em que os ritos são descritos, que não sofreram grandes alterações. Mas todas as outras partes mudaram muito. É possível que algumas pessoas transmitam essas narrativas perfeitas, esses mitos perfeitos, de uma geração para outra, mas 
eu nunca encontrei um exemplo sequer disso. Mesmo dentro de uma única aldeia, e até com os mesmos narradores, é possível encontrar diferenças, em períodos curtos de tempo. Quando os estudiosos falam de pessoas que “aprendem o mito”, é mais ou menos como se eu “aprendesse” a Bíblia. Posso aprender a Bíblia e repetir o livro do Êxodo de cor. Mas se eu não tiver a versão escrita, que diabos estarei fazendo tentando aprender o Êxodo dessa forma? Quero dizer, em primeiro lugar, que é quase impossível aprendê-lo verbalmente, de outra pessoa, desse modo. E, em segundo lugar, por que eu faria isto? “Tudo bem, eu elaborei minha própria versão e ela é tão boa quanto a outra. E, na realidade, ambas são iguais. Não vejo nenhuma diferença." Entretanto, há diferenças significativas. Se tivesse que fazer uma análise estrutural, ou uma análise funcional daquele mito, eu não poderia realmente fazê-la. Eles tiram um pouco daqui, outro pouco de lá, e depois juntam tudo e o elaboram. E depois tem as minhas coisas, como a narrativa sobre o além, ou sobre os eventos sobrenaturais, que eu reelaborei e que continuarei a reelaborar. No evento, existe uma grande variação ao longo do tempo. E já faz 40, e não 30 anos, que o faço. Fiz as primeiras anotações a mão, foi fácil, porque fiz a transcrição enquanto eu a ouvia. Mas quando você tem esse tipo de coisa, leva semanas; e se trata de uma língua que você escuta com imperfeição, pois não é sua primeira língua. E é um tipo de coisa sobre a qual você não costuma falar, sobre religião. Você enfrenta grandes dificuldades. Leva, de fato, muito tempo. É por isso que só vim a publicá-lo agora, há pouco tempo.

Peter Burke: Vamos à última pergunta que, infelizmente, é um tanto longa, sobre novas tecnologias e sobre se você acha que a revolução provocada pela Internet poderá vir a ter conseqüências tão grandes para as sociedades humanas quanto as da escrita.

Jack Goody: Não sei se é possível medir o tamanho das conseqüências, mas tenho certeza que [a Internet] é muitíssimo importante e está se tornando mais e mais importante, a cada dia que passa. O que eu quero dizer é que o comportamento das pessoas está sendo afetado. Basta você caminhar pelas ruas de Cambridge para entender o que estou dizendo. Não há como andar pelas ruas sem esbarrar em alguém que esteja falando ao telefone celular. Ele não está olhando, está falando com alguém que está a 20, ou cem, milhas de distância. No caso dos computadores portáteis a 
transformação é realmente extraordinária. Ou seja, a forma como as pessoas agem, como estão sempre registrando ou encomendando coisas pelo computador. As livrarias são uma das coisas que realmente me espantam. Há alguns dias atrás não conseguia achar um livro meu então encomendei um exemplar pela Internet e ele veio pela Amazon.com, uma firma americana. Eu ignorei a minha livraria local, o que me deixou muito mal, mas o fiz porque é muito mais fácil e chega rápido.

Peter Burke: E quando você fala em flexibilidade... considera que a mídia interativa está nos devolvendo a flexibilidade? Como que desfazendo algumas conseqüências da cultura impressa?

Jack Goody: Pode estar acontecendo isso num certo sentido. Não tenho pensado muito sobre isso. Na verdade, estou examinando uma tese sobre a tecnologia da Internet na França e já havia examinado uma outra anteriormente. Freqüentemente me pedem para examinar esse tipo de trabalho, mas receio que não tenha aprendido muito com as pesquisas que têm sido feitas nessa área. Não estou certo de que se possa falar de flexibilidade nesse caso. Veja, há uma grande procura por informação. Um dia desses estava olhando uma tese e tive a impressão de que ela estava inteiramente baseada em dados retirados da Internet. E acontece que se trata de uma área onde, se ele tivesse feito um pouco de observação direta, ou mesmo se tivesse consultado alguns documentos originais, o resultado teria ficado bem melhor. Mas a tese foi inteiramente realizada com base em material secundário. E o material secundário não estava tão bem organizado quanto deveria estar. Era como se a gente estivesse lendo o material fora dos cânones de um livro. Havia muitas partes soltas, o que é de certa forma perigoso. Ou seja, pude perceber como se pode coletar informações na Internet e formular respostas precipitadas. Você não precisa nem ir à biblioteca. Pode se fazer uma cópia e pronto. Não sei se posso considerar isso flexibilidade.

Minha impressão quanto aos meios de comunicação é que, diferentemente dos meios de produção, um não substitui o outro; acrescentase um ao outro. Não é porque somos uma sociedade letrada que vamos nos desfazer de todas as outras formas de comunicação. Isso seria uma idiotice. Os livros influenciam a nossa fala e tenho certeza que a Internet influenciará os nossos modos de pensar e de agir. Mas não acredito que se possa prever 
realmente como isso se dará. De todo modo, não creio que as previsões nessa área sejam realmente boas. Acho preferível analisar os resultados depois de ocorridos do que antes.

Pełer Burke: Precisamos, então, de mais cem anos e depois decidiremos?

Jack Goody: Acho que sim.

Peter Burke: Na verdade o que me intriga é o quanto é possível manipular o que está na tela. E agora cada vez mais com as imagens...

Jack Goody: Acho que as imagens são um aspecto muito convincente, assim como as formas como as pessoas podem usá-las. Estive, pouco tempo atrás, no Great Museum, na biblioteca de Alexandria, onde escutei uma palestra que alguém havia escrito no seu computador e incluído material visual, mas ele nem sequer havia estado lá antes, e naquele momento ele estava num outro lugar enquanto aquilo acontecia lá. Ele estava fazendo uma palestra, que na verdade não era uma palestra, pois era um documentário que tinha sido gravado. Meu filho tem todas essas imagens na web, em sua caixa, e as baixa. As imagens sobre férias e viagens podem ser muito entediantes, mas essa é uma forma de organizar a informação. Então, isso é uma hiperintensificação daquilo. Penso que acaba se tornando um vício para os estudantes de graduação, especialmente. Mas está viciando outras pessoas também, sobretudo em coisas como reservas de vôos baratos.

Peter Burke: Algumas vezes é mais rápido teclar “google.com” sentado na sua escrivaninha do que andar até o outro extremo da sala, pegar os livros e procurar pela mesma informação.

Jack Goody: Muito mais fácil. Mais fácil, particularmente, pelo jeito como funciona minha própria biblioteca. Por outro lado, há algumas insatisfações. Ou seja, não é possível folhear um livro e ao mesmo tempo voltar para confirmar a informação da mesma maneira. Você pode ler superficialmente e ao mesmo tempo ter todas as referências sobre McDougle ou quem quer que seja. Mas não pode ler superficialmente de outras maneiras.

Peter Burke: É porque não há notas de rodapé na web.

Jack Goody: Exatamente. 
Peter Burke: Então, se você pergunta às pessoas onde conseguiram isso, elas dizem que o conseguiram na Internet, o que não significa exatamente uma referência precisa a uma página ou a um livro.

Jack Goody: Sim. Penso que há vantagens que são óbvias. Uma grande ajuda para as pessoas que estão acostumadas com isso e que a preferem ao invés de ter que usar coisas como a Enciclopédia Britânica. Só precisam digitar uma pergunta e obtêm o significado disso, o significado daquilo. Em termos de comunicação é realmente incrível. Você pode se comunicar com seus filhos através de textos, como eu estou fazendo, com muito mais liberdade do que costumava fazê-lo pelo telefone. Tem a ver também com custo e outras coisas. Você se comunica com maior liberdade. Há muito mais liberdade de comunicação agora.

Peter Burke: Isso começa a aparecer nos trabalhos dos estudantes... eles estão usando as mesmas abreviações.

Jack Goody: Eles usam as mesmas abreviações que usam nos e-mails. Acredito que isso afeta o uso da linguagem de algum modo. Mas está havendo muita discussão se o uso de livros e jornais está diminuindo. Acredito que tudo indica que essas mudanças se estimulam mutuamente.

Peter Burke: Tenho certeza de que você tem razão.

Jack Goody: Como você sabe, não significa que as pessoas necessariamente estejam lendo os livros como liam antes, mas a produção de livros não parece que esteja diminuindo.

Peter Burke: E os jornais? Estamos acostumados a folheá-los de qualquer modo mais do que a lê-los propriamente. Então, ler um jornal on-line acaba não sendo tão diferente de ler um jornal impresso. Não é como ler um livro do início ao fim.

Jack Goody: Como falamos no início de nossa conversa, não estou certo, como você sabe, de que a escrita substituiu o discurso oral. Pode ter feito isso em alguma medida, mas também o ajudou a se desenvolver de outras formas, elaborando-o. Acredito que a escrita impressa ajudou também ao aumentar o público leitor. Não acredito que uma forma substituiu a outra, nem mesmo que a tenha diminuído. Ela produz certas mudanças e se soma uma à outra. 
De todo o modo, nosso desejo de comunicação vem crescendo ao longo desse percurso.

Bibliografia dos autores citados

COLE, Michael; SCRIBNER, Sylvia. The Psychology of Literacy. Cambridge, Mass.: Harvard University Press, 1981.

DIRINGER, David. The Alphabet. London: Hutchinson's, 1947.

LEAVIS, Q. D. Fiction and the Reading Public. London: Chatto \& Windus, 1932.

LLOYD, Geoffrey. Demystifying Mentalities. Cambridge: Cambridge University Press, 1990.

LORD, Albert. The Singer of Tales. Cambridge, Mass.: Harvard University Press, 1960.

OLSON, David R. The World on Paper: the Conceptual and Cognitive Implications of Writing and Reading. Cambridge: Cambridge University Press, 1994.

STREET, Brian. Literacy in Theory and Practice. Cambridge: Cambridge University Press, 1984.

WATT, Ian. The Rise of the Novel. London: Chatto \& Windus, 1957.

Transcrito por Albert William Sanches e Andrea Fachel Leal Traduzido do inglês por Daniel A. Etcheverry Revisão técnica (texto em inglês) de Maria Lúcia Pallares-Burke

Revisão técnica e edição (texto em português) de Bernardo Lewgoy, Carlos Alberto Steil e Pablo Semán 